\title{
The $\mathrm{EC}_{90}$ of remifentanil for blunting
} cardiovascular responses to head fixation for neurosurgery under total intravenous anesthesia with propofol and remifentanil based on bispectral index monitoring: estimation with the biased coin up-anddown sequential method

\author{
Jung-Man Lee ${ }^{1}$, Jae-Hyon Bahk ${ }^{2^{*}}$, Y Young-Jin Lim², Jiwon Lee ${ }^{3}$ and Leerang Lim
}

\begin{abstract}
Background: Head fixation can induce hemodynamic instability. Remifentanil is commonly used with propofol for total intravenous anesthesia (TIVA) during neurosurgery. This study investigated the $90 \%$ effective concentration (EC $C_{90}$ ) of remifentanil for blunting of cardiovascular responses to head fixation during neurosurgery via bispectral index (BIS) monitoring.

Methods: Fifty patients undergoing neurosurgery requiring head fixation were enrolled. This study was performed using the biased coin up-and-down design sequential method (BCD). After tracheal intubation, the effect-site target concentration (Ce) of remifentanil was adjusted to achieve hemodynamic stability and reset to the level preoperatively assigned to each patient, according to the BCD method, approximately 10 min before head fixation. Baseline hemodynamic values were recorded before head fixation. An ineffective response was defined as a case with a $>20 \%$ increase in hemodynamic values from baseline. Otherwise, the response was determined to be effective. The $\mathrm{EC}_{90}$ of remifentanil was calculated as a modified isotonic estimator.
\end{abstract}

Results: Forty-three patients completed this study. The $\mathrm{EC}_{90}$ of remifentanil for blunting cardiovascular responses to head fixation was estimated to be $6.48 \mathrm{ng} / \mathrm{mL}(95 \% \mathrm{Cl}, 5.94-6.83 \mathrm{ng} / \mathrm{mL})$.

Conclusions: Adjustment of the Ce of remifentanil to approximately $6.5 \mathrm{ng} / \mathrm{mL}$ before head fixation could prevent noxious cardiovascular responses in 90\% of neurosurgical ASA I-II patients aged 20 to 65 years old during propofol target-controlled infusion titrated to maintain BIS between 40 and 50.

Trial registration: ClinicalTrials.gov Identifier NCT01489137, retrospectively registered 5 December 2011.

Keywords: Head fixation, Neurosurgery, Remifentanil

\footnotetext{
* Correspondence: bahkjh@snu.ac.kr

${ }^{2}$ Department of Anesthesiology and Pain Medicine, Seoul National University

Hospital, Seoul National University College of Medicine, 101, Daehak-ro,

Jongno-gu, Seoul 03080, Republic of Korea

Full list of author information is available at the end of the article
} 


\section{Background}

A head holder is commonly used to stabilize the head during neurosurgery. Skull pin insertion, head pinning, and pin fixation are synonyms for head fixation and indicate the application of a head holder. Use of a head holder is of paramount importance during stereotactic neurosurgery. However, anesthesiologists may encounter hemodynamic changes that require pharmacological intervention due to a noxious stimulus resulting from head fixation. Acute arterial hypertension can lead to intracranial hemorrhage [1, 2]. Therefore, various strategies have been used to reduce the degree of hemodynamic changes induced by head fixation, resulting in various recommendations [3-7].

Recently, total intravenous anesthesia (TIVA) has become a widely used method for general anesthesia. Among various combinations of intravenous anesthetics, continuous propofol infusion and opioid supplementation is a widely used combination. TIVA is considered a standard method of general anesthesia, especially for evoked potential monitoring [8]. Due to its pharmacodynamic and pharmacokinetic characteristics, such as a very short context-sensitive half-time and minimal effects on cardiovascular system, remifentanil is a commonly used opioid in conjunction with propofol for TIVA.

This study was designed to estimate the 90\% effective concentration $\left(\mathrm{EC}_{90}\right)$ of remifentanil for blunting cardiovascular responses to head fixation during neurosurgery under TIVA with bispectral index (BIS) monitoring.

\section{Methods}

This study was approved by the Institutional Review Board of the Seoul National University Hospital. Written informed consent was obtained from all patients. The trial was registered at www.clinicaltrials.gov (NCT01489137). American Society of Anesthesiologists physical status I-II patients were enrolled in this study. The patients were 20-65 years old and were scheduled to undergo elective neurosurgery requiring head fixation. Patients who were obese (body mass index $>30.0$ ) or severely underweight (body mass index <16.0), had hypertension, cardiac disease, pulmonary disease, or renal disease, used current medication affecting the cardiovascular system, or were addicted to substances or alcohol were excluded from this study. Furthermore, patients who were administered any drugs that affect the cardiovascular system, such as ephedrine, during the period from the induction of anesthesia to head fixation were excluded.

\section{Anesthesia}

Prior to the surgery, patients fasted for $8 \mathrm{~h}$ and received no premedication. A standard monitoring and anesthetic technique was applied to all patients in the operating room. All patients received TIVA with propofol and remifentanil using a target-controlled infusion (TCI) system under BIS monitoring with the BIS VISTA ${ }^{\mathrm{Tm}}$ system (Aspect Medical Systems, Newton, MA, USA). The Schnider and Minto models were selected as the pharmacokinetic models for propofol and remifentanil, respectively $[9,10]$. The TCI mode was set to the effectsite control using an Orchestra ${ }^{\mathrm{TM}}$ device (Fresenius Vial, France).

The same effect-site target concentrations (Ce) of propofol $(4 \mu \mathrm{g} / \mathrm{mL})$ and remifentanil $(4 \mathrm{ng} / \mathrm{mL})$ were given to all patients for anesthetic induction. After induction of anesthesia, the lungs of patients were ventilated via manual bagging, and $0.8 \mathrm{mg} / \mathrm{kg}$ rocuronium was administered. After muscle relaxation, an anesthesiologist inserted a 20-G catheter into the radial artery to monitor continuous arterial blood pressure during the operation. Then, tracheal intubation was performed. Infusion of $0.9 \%$ normal saline $(10 \mathrm{~mL} / \mathrm{kg})$ was performed during the trial to compensate for dehydration from overnight fasting, which was completed before recording baseline hemodynamics.

\section{Study design and setting}

At approximately $10 \mathrm{~min}$ before head fixation, the propofol Ce was adjusted to maintain the BIS at approximately early 40 s, but over than 40 . During the remainder of the operation, the propofol Ce was adjusted to maintain the BIS at between 40 and 50. After endotracheal intubation, the remifentanil Ce was adjusted to stabilize the hemodynamic responses. The remifentanil Ce was reset to the preoperatively assigned level at least $10 \mathrm{~min}$ before the initiation of head fixation. This was performed by the same anesthesiologist in each case: the anesthesiologist opened an envelope containing a card stating the remifentanil Ce assigned to the patient and then adjusted the $\mathrm{Ce}$ to the assigned level by modulating the TCI pump for the patient. A second, standing anesthesiologist managed the patient for the whole operation and recorded the vital signs during head fixation. The standing anesthesiologist was blinded to the remifentanil Ce by covering the screen of the Orchestra ${ }^{\mathrm{Tm}}$ device with a sheet of paper during the study. Before the study, the standing anesthesiologist was ordered to only administer vasoactive drugs such as ephedrine in cases in which the mean arterial blood pressure (MAP) decreased to $<55 \mathrm{mmHg}$ before head fixation. The MAP and heart rate (HR) were recorded by a standing anesthesiologist at 1 and $2 \mathrm{~min}$ before head fixation, and the means of these readings were calculated and used as the baseline values $\left(\mathrm{MAP}_{\mathrm{BL}}\right.$ and $\left.\mathrm{HR}_{\mathrm{BL}}\right)$. Neurosurgeons performed head fixation without any local infiltration of anesthetics at the pin site or use of a scalp nerve block. The MAP and HR were monitored and recorded during head fixation and the immediate post-fixation period. 
The peak values during head fixation were recorded to determine their primary end-points, which were defined as the percentage increases compared to the $\mathrm{MAP}_{\mathrm{BL}}$ and $\mathrm{HR}_{\mathrm{BL}}$ ([peak value - baseline]/baseline $\times 100 \%$ ). After completion of head fixation, the MAP and HR were observed for $5 \mathrm{~min}$, and the values were recorded each $\mathrm{mi}$ nute. Figure 1 shows the timeline of the study.

A vasoactive drug or $\beta$-agonist was prepared for administration if the MAP decreased to $<55 \mathrm{mmHg}$ or the HR decreased to $<45 / \mathrm{min}$. Subjects who were administered these drugs before head fixation were excluded from the study. We were also prepared to inject appropriate drugs if the MAP and HR did not return to within $120 \%$ of baseline values within 3 min after head fixation.

\section{Statistical analyses}

The $\mathrm{EC}_{90}$ of remifentanil that attenuated the cardiovascular responses to head fixation was estimated using the biased coin up-and-down design sequential method (BCD) [11]. The remifentanil Ce for the first subject was set to $5.5 \mathrm{ng} / \mathrm{mL}$ based on our past clinical experience. The remifentanil Ce for the next patient was determined by the responses of the previous subject who had completed the trial; a Ce difference of $0.5 \mathrm{ng} / \mathrm{mL}$ was chosen as our step size. In case of failure to attenuate the hemodynamic responses to head fixation, (> 20\% increase in $\mathrm{MAP}_{\mathrm{BL}}$ or $\mathrm{HR}_{\mathrm{BL}}$ ), the following subject would receive a higher $\mathrm{Ce}$ at an increment of $0.5 \mathrm{ng} / \mathrm{mL}$. If the change was within a $20 \%$ increase for both the $\mathrm{MAP}_{\mathrm{BL}}$ and $\mathrm{HR}_{\mathrm{BL}}$ (thus, the remifentanil Ce was effective), the remifentanil $\mathrm{Ce}$ for the next subject was randomly assigned with a probability of 0.89 (8/9) of a Ce decrement of $0.5 \mathrm{ng} / \mathrm{mL}$ from the prior subject's Ce or a probability of $0.11(1 / 9)$ of the same Ce as the prior subject. If a subject was excluded for any reason, the subsequent subject was given the $\mathrm{Ce}$ assigned to the excluded subject.

A sample size of at least 40 was determined according to a statistical reference [12]. The $\mathrm{EC}_{90}$ was estimated by calculating a modified isotonic estimator (MIE) [12].
The $\mathrm{R}$ 2.14.1 program ( $\mathrm{R}$ foundation for Statistical Computing, Vienna, Austria) was used for this calculation. The 95\% confidence interval (CI) was obtained using a parametric bootstrap routine and calculated by a biascorrected percentile method [11].

\section{Results}

Fifty patients were enrolled in the study. Seven patients were excluded due to the use of ephedrine to treat hypotension prior to head fixation $(n=4)$, inadequate steady-state time $(<10 \mathrm{~min})$ from reset of the remifentanil Ce to head fixation $(n=2)$, and topical infiltration of $1 \%$ lidocaine with epinephrine $(1: 200,000)$ for nasal mucosa vasoconstriction prior to head fixation in a tumorectomy with a trans-sphenoidal approach $(n=1)$.

A total of 43 patients completed this study, and their data were analyzed. The remifentanil Ce ranged from 5.0 to $7.0 \mathrm{ng} / \mathrm{mL}$ according to the BCD method (Fig. 2).

The patients' clinical characteristics are listed in Table 1. Among the 43 subjects who completed the study, seven experienced hemodynamic changes characterized by a $>20 \%$ increase in their $\mathrm{MAP}_{\mathrm{BL}}$ or $\mathrm{HR}_{\mathrm{BL}}$ values. Thus, the remifentanil Ce used in these subjects was not sufficient to alleviate their hemodynamic responses to head fixation. Although these were recorded as failures, the severity of the change was not sufficient to require antihypertensive drugs. The hemodynamic changes in the remaining subjects were characterized by $\leq 20 \%$ increases from baseline values, and these were considered effective cases. In all cases, the MAP and HR returned to within $120 \%$ of the baseline value within 2 and $1 \mathrm{~min}$, respectively.

The BIS of 42 of the 43 subjects increased. The change in the BIS among all 43 subjects was $6.6 \pm 3.0$ (mean \pm SD). The BIS decreased by only 1 in one subject.

The calculated $\mathrm{EC}_{90}$ of remifentanil was $6.48 \mathrm{ng} / \mathrm{mL}$ (95\% CI, 5.96-6.83 ng/mL). Figure 3 shows changes in the MAP and HR in subjects with remifentanil Ce values of $6.0(n=10), 6.5(n=21)$, and $7.0 \mathrm{ng} / \mathrm{mL}(n=5)$, which were similar to the $E_{90}$ calculated using our

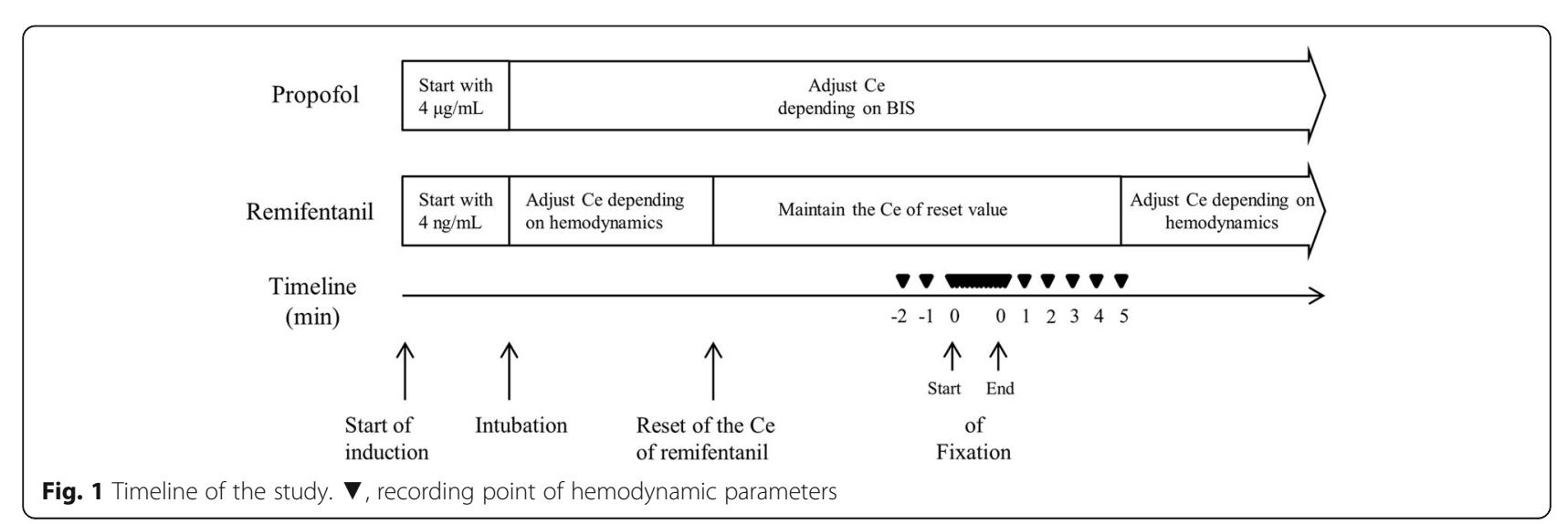




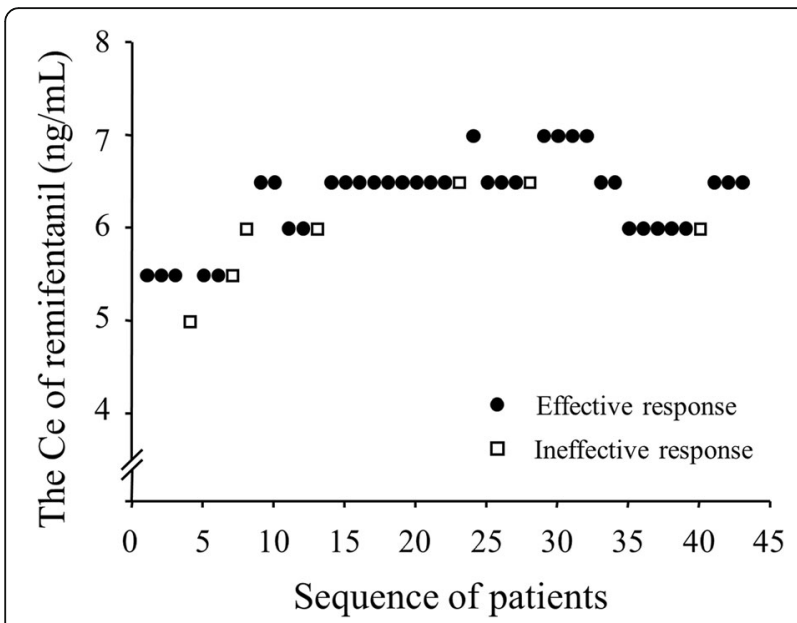

Fig. 2 Remifentanil Ce assignment and patient responses. The remifentanil Ce for the first subject was $5.5 \mathrm{ng} / \mathrm{mL}$. The Ce assigned to sequential subjects was determined by the biased coin design up-and-down sequential method. Ce, effect-site target concentration

results. We also calculated the $\mathrm{EC}_{50}(5.33 \mathrm{ng} / \mathrm{mL} ; 95 \%$ CI, 5.27-5.44 ng/mL) and $\mathrm{EC}_{95}(6.74 \mathrm{ng} / \mathrm{mL} ; 95 \% \mathrm{CI}$, $6.28-6.93 \mathrm{ng} / \mathrm{mL})$.

\section{Discussion}

In this study, the $\mathrm{EC}_{90}$ of remifentanil was calculated as $6.48 \mathrm{ng} / \mathrm{mL}$ (95\% CI, 5.96-6.83 ng/mL). This Ce is approximately $20 \%$ higher than that typically used in our hospital (5.5 ng/mL).

Previously, several studies have investigated the most effective method of alleviating hemodynamic responses to head fixation [3-7]. The authors introduced and compared various strategies, such as intravenous opioids, local anesthetic infiltration at the pin sites, a combination of intravenous fentanyl and local anesthetic infiltration, and scalp nerve blockade. However, no consensus exists to guide anesthesiologists in attenuating cardiovascular responses to head fixation. In our experience, intravenous

Table 1 Clinical characteristics of the 43 subjects who completed the study

\begin{tabular}{ll}
\hline Variables & Mean \pm SD \\
\hline Males / females $(\mathrm{n})$ & $20^{\mathrm{a}} / 23^{\mathrm{a}}$ \\
Age $(\mathrm{y})$ & $46.6 \pm 11.0$ \\
Weight $(\mathrm{kg})$ & $64.1 \pm 11.2$ \\
Height $(\mathrm{cm})$ & $163.5 \pm 9.1$ \\
BMI $\left(\mathrm{kg} / \mathrm{m}^{2}\right)$ & $23.9 \pm 3.1$ \\
Ce of Propofol during fixation $(\mu \mathrm{g} / \mathrm{mL})$ & $2.9 \pm 0.7$ \\
BIS prior to fixation & $41.2 \pm 2.0$ \\
Baseline MAP (mmHg) & $77.4 \pm 11.7$ \\
Baseline HR (beats/min) & $61.7 \pm 9.8$ \\
\hline BMl body mass index. Ce, effect-site target concentration. The resuls are
\end{tabular}

$B M I$ body mass index. $\mathrm{Ce}$, effect-site target concentration. The results are presented as the mean \pm SD or numbers ${ }^{a}$ fentanyl injection alone may not be sufficiently effective in many cases, and local anesthetic infiltration may not always be effective because sometimes the exact pin sites may not match the infiltrated scalp area. Furthermore, in some cases, surgeons reposition the skull pins after their first attempt at head fixation. We perform scalp nerve blockade as a routine practice in patients undergoing awake craniotomy. In our experience, the effect of scalp nerve blockade is usually highly potent. A previous study showed an approximately $6.8 \%$ increase in the MAP from the $\mathrm{MAP}_{\mathrm{BL}}$ due to head fixation in patients who received scalp nerve block with bupivacaine [7]. In our study, the increase in MAP in patients with a remifentanil Ce of $6.5 \mathrm{ng} / \mathrm{mL}$ was approximately $12.3 \%$. However, scalp nerve block is not always effective, and its performance requires extra time and training.

As mentioned previously, remifentanil has excellent characteristics and is commonly used, along with propofol, by anesthesiologists for TIVA with a TCI system during neurosurgery. If a remifentanil Ce that effectively reduces hemodynamic responses to head fixation is attained, the anesthesiologists can maintain a stable hemodynamic status with fewer drugs and use a simpler approach.

Recently, a similar study was conducted to determine the $\mathrm{EC}_{50}$ of remifentanil necessary to minimize the cardiovascular changes due to head fixation under TIVA with BIS monitoring [13]. The authors in that study used the Dixon up-and-down sequential allocation method. They found that the $\mathrm{EC}_{50}$ of remifentanil was $2.90 \mathrm{ng} /$ $\mathrm{mL}$ (95\% CI, $1.78-3.65 \mathrm{ng} / \mathrm{mL}$ ) and showed that the $\mathrm{EC}_{95}$ was $4.28 \mathrm{ng} / \mathrm{mL}(95 \% \mathrm{CI}, 3.85-4.41 \mathrm{ng} / \mathrm{mL})$ via isotonic regression estimation. These values were lower than our results.

Several differences existed between their study and ours. First, we used the BCD method, but they used the Dixon up-and-down method (UDM). Second, while we defined the $\mathrm{MAP}_{\mathrm{BL}}$ and $\mathrm{HR}_{\mathrm{BL}}$ values as the levels observed during the steady state at 1-2 min before the head fixation, they defined the baseline values as the levels observed before induction of anesthesia. Third, we adjusted the propofol Ce based on the BIS in our study, but they fixed the propofol Ce during the trial.

We used the BCD method to determine the $\mathrm{EC}_{90}$ of remifentanil for alleviation of cardiovascular responses due to head fixation. Many preliminary studies have used the UDM of Dixon and Mood to determine the $\mathrm{ED}_{50} / \mathrm{EC}_{50}$. The UDM was designed to estimate the median threshold, including the $\mathrm{ED}_{50}$ or $\mathrm{EC}_{50}[11,14]$. Although it would be possible to estimate the $\mathrm{ED}_{90} / \mathrm{EC}_{90}$ or $\mathrm{ED}_{95} / \mathrm{EC}_{95}$ by extrapolation in a UDM study, extrapolation of a high-quantile effect dose/concentration from the tolerance distribution curve determined by the UDM is not adequate due to weak precision [11]. Therefore, 

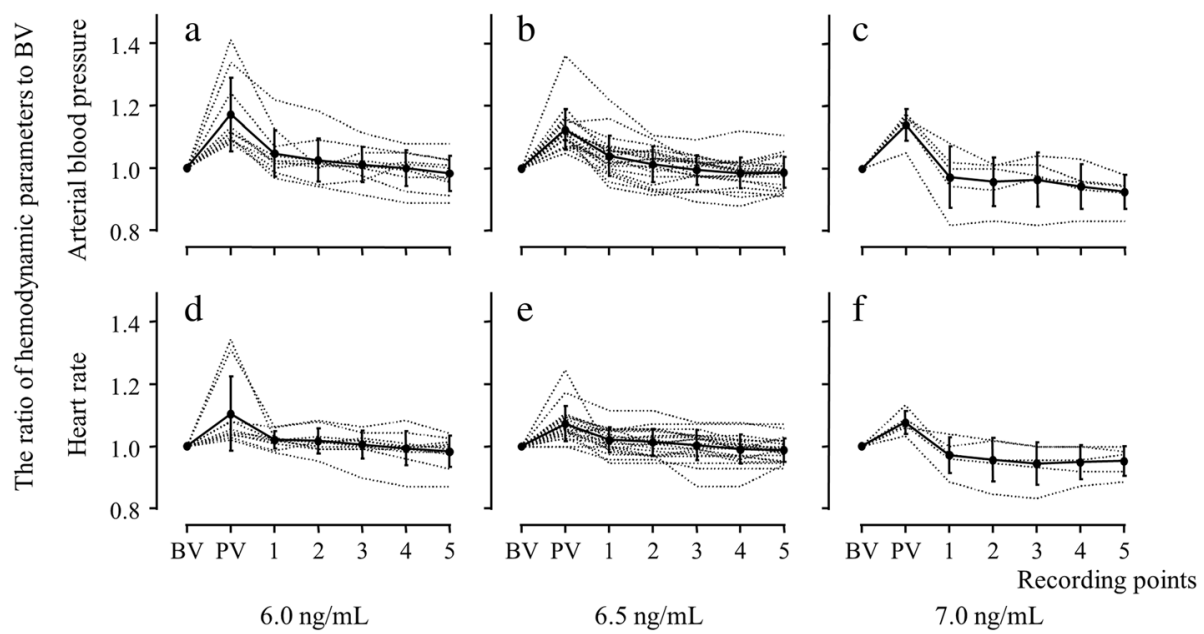

Ce of remifentanil

Fig. 3 Changes in the mean arterial blood pressure and heart rate of subjects with remifentanil Ce values of $6.0(n=10), 6.5(n=21)$ and 7.0 $(n=5) \mathrm{ng} / \mathrm{mL}$. The $Y$ axis in all figures [(a) to $(\mathbf{f})]$ represents the ratio of hemodynamic parameters to baseline values. The $X$ axis represents the time-points at which hemodynamic parameters were recorded. $\mathbf{a}, \mathbf{b}$, and $\mathbf{c}$ show the arterial blood pressure ratio compared to baseline values in patients assigned to a remifentanil Ce of $6.0,6.5$ and $7.0 \mathrm{ng} / \mathrm{mL}$, respectively. $\mathbf{d}$, e, and $\mathbf{f}$ show the heart rate ratio compared to baseline values in patients assigned to a remifentanil Ce of $6.0,6.5$ and $7.0 \mathrm{ng} / \mathrm{mL}$, respectively. BV indicates the baseline values of hemodynamic parameters; PV indicates peak value of hemodynamic parameters immediately after head fixation; Ce is the effect-site target concentration; the numbers 1, 2, 3, 4 and 5 on the X-axis represent the time (min) after fixation

the BCD method is more suitable for determining the high-quantile effect dose/concentration because a $\mathrm{BCD}$ study can be performed to target the $\mathrm{EC}_{90}$, permitting a direct estimation of the $\mathrm{EC}_{90}$ and avoiding unverifiable extrapolations from the $\mathrm{EC}_{50}$ value [11]. Although, the $\mathrm{EC}_{95}$ would be more attractive to clinicians, a previous study showed that a sample size of 40 resulted in significantly less precision than determination of the $\mathrm{EC}_{90}$ using a simulation test [15]. Therefore, we determined the $\mathrm{EC}_{90}$ using the $\mathrm{BCD}$ method with a sample size of about 40 .

We used the MAP and HR values 1-2 min before head fixation as baseline hemodynamic values. In neurosurgery on the brain, acute arterial hypertension may induce intracranial hypertension in patients with intracranial tumors and peritumoral edema [16]. In addition, a previous study reported that intracranial pressure could be rapidly increased by head fixation in patients with a brain tumor [2]. So, we used these values as baseline values of MAP and HR because we thought it should be important to prevent the abrupt increase of hemodynamics due to head fixation.

In the present study, we aimed to maintain BIS values at between 40 and 50 during the operative period and at approximately early $40 \mathrm{~s}$, but $\geq 40$, immediately before head fixation. BIS values between 40 and 60 are recommended as an adequate level for general anesthesia in several studies $[17,18]$. Another recommendation states that the BIS should be greater than 45 because BIS values below 45 are associated with increased mortality
[19-22]. Sessler et al. introduced the 'Triple low' concept (low minimum alveolar concentration (MAC), low MAP, and low BIS), which was a strong and highly statistically significant predictor of mortality [23]. However, the authors of the study interpreted the finding to indicate that high-risk patients were sensitive to anesthetics rather than as an indication that the 'Triple low' (low MAC, low MAP, and low BIS) was a causative factor of high mortality. Several previous studies have supported Sessler's study [22, 24, 25]. However, some studies have also provided conflicting results on this issue [26, 27]. A recent study found that a "smart alarm" to indicate the 'Double low' (low MAP < $75 \mathrm{mmHg}$ and a low BIS <45) did not decrease mortality [28]. Moreover, we found that the 30-day, 90-day, 1-year, and 5-year mortality rates were $0 / 43,1 / 43,3 / 43$, and $3 / 43$, respectively, in our study. This result is comparable to previous studies, even with the small sample size of our study [22, 28, 29].

A previous study reported that a BIS value between 50 and 60 prior to tracheal intubation was inadequate to prevent an awareness reaction to tracheal intubation during propofol/alfentanil anesthesia, although no recall case was included in that study [30]. In addition, two case reports and one randomized controlled trial presented awareness reactions despite use of the recommended BIS level, 40$60[31,32]$. Therefore, we maintained the BIS between 40 and 50 during whole operation, and a target BIS value near 40 (but $\geq 40$ ) was used just before head fixation to avoid awareness. 
No patients experienced bradycardia $(\mathrm{HR}<45)$ in this study. However, four subjects experienced hypotension with an MAP of $<55 \mathrm{mmHg}$ and were administered ephedrine. The incidence of hypotension resulting from the use of a remifentanil Ce of $6.5 \mathrm{ng} / \mathrm{mL}$ in this study was $8.7 \%(2 / 23)$. Based on our experience, hypotension is not uncommon during neurosurgery using this anesthetic technique.

A limitation of our study was that the subjects did not represent the entire group of patients who required head fixation for craniotomy. Twenty-seven patients were excluded prior to consent due to a diagnosis of hypertension during the pre-assessment. These subjects were excluded because patients with chronic hypertension can show an exaggerated response to noxious stimulation [33]. Further research into safer use of remifentanil in a more heterogeneous patient population with an unstable hemodynamic status, such as hypertension, is needed. A combination of propofol and remifentanil anesthesia using TCI with local anesthetic injection at the pin site or scalp nerve blockade might be an appropriate strategy for patients with an unstable hemodynamic status. Remifentanil Ce values that are lower than that calculated in the present study $(6.5 \mathrm{ng} /$ $\mathrm{mL}$ ) may be needed to maintain stable vital signs in patients receiving a combination of TIVA with local injection, scalp nerve block or any premedication; this should be verified in future studies. We determined that an $\mathrm{EC}_{90}$ of remifentanil of $6.5 \mathrm{ng} / \mathrm{mL}$ is necessary to alleviate hemodynamic instability caused by head fixation in a small sample of patients $(n=43)$ using the BCD method. However, this sample size is not sufficient to generalize our results to all patients requiring head fixation. Therefore, further studies are needed to validate our results.

\section{Conclusions}

Adjustment of the remifentanil Ce to approximately $6.5 \mathrm{ng} / \mathrm{mL}$ before head fixation could prevent noxious cardiovascular responses in $90 \%$ of neurosurgical ASA I-II patients aged 20 to 65 years old during propofol TCI titrated to maintain BIS between 40 and 50 .

\section{Abbreviations}

BCD: biased coin design up-and-down sequential method; Ce: effect-site target concentration; EC: effective concentration; $\mathrm{EC}_{90}$ : $90 \%$ effective concentration; ED: effective dose; HR: heart rate; $H R_{B L}$ : baseline heart rate; MAC: minimum alveolar concentration; MAP: mean arterial blood pressure; $\mathrm{MAP}_{\mathrm{BL}}$ : baseline mean arterial blood pressure; MIE: modified isotonic estimator; TCl: target-controlled infusion; TIVA: total intravenous anesthesia; UDM: up-and-down method
}

\section{Acknowledgements}

We would like to thank Department of Medical Research Collaborating Center (MRCC) of Seoul National University Hospital for the professional help with the statistical works.

\section{Availability of data and materials}

The datasets generated and analysed during the current study are available from the corresponding author on reasonable request.

\section{Authors' contributions}

JML participated in the design of the study, data acquisition, the statistical analysis, the data interpretation, revised and drafted the manuscript. JHB participated in the design of study, the data interpretation and revised the manuscript. YJL participated in the data acquisition and the data interpretation. $J L$ participated in the data interpretation, revised and drafted the manuscript. LL revised and drafted the manuscript. All authors read and approved the final manuscript.

\section{Funding}

This work was supported by Seoul National University Hospital, Seoul National University College of Medicine, Republic of Korea.

\section{Ethics approval and consent to participate}

This study was approved by the institutional review board of Seoul National University Hospital. (H-1110-095-382). All participants provided written informed consent prior to the initiation of the study.

\section{Consent for publication}

Not applicable.

Competing interests

The authors declare that they have no competing interests.

\section{Publisher's Note}

Springer Nature remains neutral with regard to jurisdictional claims in published maps and institutional affiliations.

\section{Author details}

'Department of Anesthesiology and Pain Medicine, Seoul Metropolitan Government Seoul National University Boramae Medical Center, 20, Boramae-ro 5-gil, Dongjak-gu, Seoul 07061, Republic of Korea. ${ }^{2}$ Department of Anesthesiology and Pain Medicine, Seoul National University Hospital, Seoul National University College of Medicine, 101, Daehak-ro, Jongno-gu, Seoul 03080, Republic of Korea. ${ }^{3}$ Department of Anesthesiology and Pain Medicine, Keimyung University Dongsan Medical Center, Keimyung University College of Medicine, 56, Dalseong-ro, Daegu 41931, Republic of Korea. ${ }^{4}$ Department of Anesthesiology and Pain Medicine, Seoul National University Hospital, 101, Daehak-ro, Jongno-gu, Seoul 03080, Republic of Korea

Received: 10 June 2017 Accepted: 2 October 2017

Published online: 10 October 2017

\section{References}

1. Engberg M, Melsen NC, Herlevsen P, Haraldsted V, Cold GE. Changes of blood pressure and cerebral arterio-venous oxygen content differences (AVDO2) with and without bupivacaine scalp infiltration during craniotomy. Acta Anaesthesiol Scand. 1990;34(5):346-9.

2. Shapiro HM, Wyte SR, Harris AB, Galindo A. Acute intraoperative intracranial hypertension in neurosurgical patients: mechanical and pharmacologic factors. Anesthesiology. 1972;37(4):399-405.

3. Geze S, Yilmaz AA, Tuzuner F. The effect of scalp block and local infiltration on the haemodynamic and stress response to skull-pin placement for craniotomy. Eur J Anaesthesiol. 2009;26(4):298-303.

4. Yildiz K, Madenoglu H, Dogru K, Kotanoglu MS, Akin A, Boyaci A. The effects of intravenous fentanyl and intravenous fentanyl combined with bupivacaine infiltration on the hemodynamic response to skull pin insertion. J Neurosurg Anesthesiol. 2005;17(1):9-12.

5. Ozkose Z, Yardim S, Yurtlu S, Dogulu F, Kaymaz M, Pasaoglu A. The effects of intravenous fentanyl and lidocaine infiltration on the hemodynamic response to skull pin placement. Neurosurg Rev. 2001;24(1):35-7.

6. Doblar DD, Lim YC, Baykan N, Frenette L. A comparison of alfentanil, esmolol, lidocaine, and thiopental sodium on the hemodynamic response to insertion of headrest skull pins. J Clin Anesth. 1996;8(1):31-5. 
7. Pinosky ML, Fishman RL, Reeves ST, Harvey SC, Patel S, Palesch Y, Dorman $\mathrm{BH}$. The effect of bupivacaine skull block on the hemodynamic response to craniotomy. Anesth Analg. 1996;83(6):1256-61.

8. Sloan TB, Jäntti V. Anesthetic effects on evoked potentials. In: Nuwer MR, editor. Intraoperative Monitoring of Neural Function. Volume 8, edn. New York: Elsevier; 2008. p. 94-126.

9. Schnider TW, Minto CF, Shafer SL, Gambus PL, Andresen C, Goodale DB, Youngs EJ. The influence of age on propofol pharmacodynamics. Anesthesiology. 1999;90(6):1502-16.

10. Minto CF, Schnider TW, Shafer SL. Pharmacokinetics and pharmacodynamics of remifentanil. II. Model application. Anesthesiology. 1997;86(1):24-33.

11. Pace NL, Stylianou MP. Advances in and limitations of up-and-down methodology: a precis of clinical use, study design, and dose estimation in anesthesia research. Anesthesiology. 2007;107(1):144-52.

12. Stylianou M, Flournoy N. Dose finding using the biased coin up-and-down design and isotonic regression. Biometrics. 2002;58(1):171-7.

13. Do WS, Kim TK, Kim HK, Kim CH. The EC(50) of remifentanil to minimize the cardiovascular changes during head holder pinning in neurosurgery. Korean J Anesthesiol. 2012;63(4):327-33.

14. Oron AP: Stationary and convergence properties of'Up-and-Down'methods. 2006.

15. George RB, McKeen D, Chaplin AC, McLeod L. Up-down determination of the $\mathrm{ED}(90)$ of oxytocin infusions for the prevention of postpartum uterine atony in parturients undergoing Cesarean delivery. Can J Anaesth. 2010; 57(6):578-82.

16. Bedford RF, Morris L, Jane JA. Intracranial hypertension during surgery for supratentorial tumor: correlation with preoperative computed tomography scans. Anesth Analg. 1982;61(5):430-3.

17. Sebel PS, Lang E, Rampil IJ, White PF, Cork R, Jopling M, Smith NT, Glass PS, Manberg P. A multicenter study of bispectral electroencephalogram analysis for monitoring anesthetic effect. Anesth Analg. 1997;84(4):891-9.

18. Liu J, Singh H, White PF. Electroencephalographic bispectral index correlates with intraoperative recall and depth of propofol-induced sedation. Anesth Analg. 1997:84(1):185-9.

19. Gan TJ, Glass PS, Windsor A, Payne F, Rosow C, Sebel P, Manberg P. Bispectral index monitoring allows faster emergence and improved recovery from propofol, alfentanil, and nitrous oxide anesthesia. BIS Utility Study Group. Anesthesiology. 1997;87(4):808-15.

20. Monk TG, Saini V, Weldon BC, Sigl JC. Anesthetic management and oneyear mortality after noncardiac surgery. Anesth Analg. 2005;100(1):4-10.

21. Lindholm ML, Traff S, Granath F, Greenwald SD, Ekbom A, Lennmarken C, Sandin $\mathrm{RH}$. Mortality within 2 years after surgery in relation to low intraoperative bispectral index values and preexisting malignant disease. Anesth Analg. 2009;108(2):508-12.

22. Kertai MD, Palanca BJ, Pal N, Burnside BA, Zhang L, Sadiq F, Finkel K, Avidan MS, Group BUS. Bispectral index monitoring, duration of bispectral index below 45, patient risk factors, and intermediate-term mortality after noncardiac surgery in the B-Unaware Trial. Anesthesiology. 2011;114(3):545-56

23. Sessler DI, Sigl JC, Kelley SD, Chamoun NG, Manberg PJ, Saager L, Kurz A, Greenwald S. Hospital stay and mortality are increased in patients having a "triple low" of low blood pressure, low bispectral index, and low minimum alveolar concentration of volatile anesthesia. Anesthesiology. 2012;116(6): 1195-203.

24. Leslie K, Short TG. Low bispectral index values and death: the unresolved causality dilemma. Anesth Analg. 2011;113(3):660-3.

25. Maheshwari A, McCormick PJ, Sessler DI, Reich DL, You J, Mascha EJ, Castillo $J G$, Levin MA, Duncan AE. Prolonged concurrent hypotension and low bispectral index ('double low') are associated with mortality, serious complications, and prolonged hospitalization after cardiac surgery. $\mathrm{Br} \mathrm{J}$ Anaesth. 2017;119(1):40-9.

26. Willingham MD, Karren E, Shanks AM, O'Connor MF, Jacobsohn E, Kheterpal S, Avidan MS. Concurrence of Intraoperative Hypotension, Low Minimum Alveolar Concentration, and Low Bispectral Index Is Associated with Postoperative Death. Anesthesiology. 2015;123(4):775-85.

27. Kertai MD, White WD, Gan TJ. Cumulative duration of "triple low" state of low blood pressure, low bispectral index, and low minimum alveolar concentration of volatile anesthesia is not associated with increased mortality. Anesthesiology. 2014;121(1):18-28.

28. McCormick PJ, Levin MA, Lin HM, Sessler DI, Reich DL. Effectiveness of an Electronic Alert for Hypotension and Low Bispectral Index on 90-day
Postoperative Mortality: A Prospective, Randomized Trial. Anesthesiology. 2016;125(6):1113-20.

29. Siqueira EMP, Diccini S. Postoperative complications in elective and nonelective neurosurgery. Acta Paul Enferm. 2017;30(1):101-8.

30. Schneider G, Wagner K, Reeker W, Hanel F, Werner C, Kochs E. Bispectral Index (BIS) may not predict awareness reaction to intubation in surgical patients. J Neurosurg Anesthesiol. 2002;14(1):7-11.

31. Rampersad SE, Mulroy MF. A case of awareness despite an "adequate depth of anesthesia" as indicated by a Bispectral Index monitor. Anesth Analg. 2005;100(5):1363-4.

32. Myles PS, Leslie K, McNeil J, Forbes A, Chan MT. Bispectral index monitoring to prevent awareness during anaesthesia: the B-Aware randomised controlled trial. Lancet. 2004;363(9423):1757-63.

33. Low JM, Harvey JT, Prys-Roberts C, Dagnino J. Studies of anaesthesia in relation to hypertension. VII: Adrenergic responses to laryngoscopy. $\mathrm{Br}$ J Anaesth. 1986:58(5):471-7.

\section{Submit your next manuscript to BioMed Central and we will help you at every step:}

- We accept pre-submission inquiries

- Our selector tool helps you to find the most relevant journal

- We provide round the clock customer support

- Convenient online submission

- Thorough peer review

- Inclusion in PubMed and all major indexing services

- Maximum visibility for your research

Submit your manuscript at www.biomedcentral.com/submit
Biomed Central 